\title{
RENE 220: IN RETROSPECT AND PROSPECT
}

\author{
Edward A. Loria \\ Metallurgical Consultant \\ 1828 Taper Drive \\ Pittsburgh, Pennsylvania 15241
}

\begin{abstract}
Increasing the maximum operating temperature is a vital design objective in aero gas turbines and Rene 220 exhibits an enhanced tompcrature capability of $100^{\circ} \mathrm{F}$ over Alloy 718. The cast version $220 \mathrm{C}$ has gained commercial acceptance for the production of structural castings such as turbine frames. Acceptance of the wrought version $220 \mathrm{~W}$ has been postponed because of a high hold time crack growth rate which could not be tolerated in a turbine disk or shaft. This report reviews the few papers that exist in the open literature and emphasizes the salient features in retrospect. Then, in prospect, it describes a modified composition which would provide a different microstructure during wrought processing and an acceptable fatigue crack growth resistance.
\end{abstract}

\section{Introduction}

As a derivative of Alloy 718, Rene 220 deserves attention in this symposium. This GE alloy, invented by Keh-Minn Chang, 1-2 has a $\mathrm{Ni}$ base and nominal composition of $19 \mathrm{Cr}-12 \mathrm{Co}-5 \mathrm{Nb}-0.5 \mathrm{AI}-$ $1 \mathrm{Ti}-3 \mathrm{Ta}$ plus $0.03 \mathrm{C}$ and $0.003 \mathrm{~B}$ in wt pct. Capable of sustaining more than $27^{\circ} \mathrm{C}\left(100^{\circ} \mathrm{F}\right)$ increase in service temperature relative to Alloy 718, it has equal or better castability and superior weldability. The alloy's better mechanical properties and weldability are attributed to the substitution of cobalt for iron and the addition of tantalum.

Because of the absence of iron, Rene $220 \mathrm{C}$ does not form large amounts of Laves phase on solidification, either during casting or welding. During welding, heat affected zone grain boundaries open up as much as in Alloy 718 but little Laves phase forms on solidification, precluding microcracks. Moreover, the alloy forms a more stable $\delta$ phase due to the presence of tantalum which further improves weldability. 
Because of these features, Rene $220 \mathrm{C}$ has gained commercial acceptance for the production of structural (investment) castings, such as turbine frames of aircraft engines. However, acceptance of the wrought version, Rene $220 \mathrm{w}$ has been shelved (postponed) because of a high hold time crack growth rate which could occur in a wrought product such as a turbine disk or shaft.

In the spirit of giving Rene 220 some attention in this symposium, this report reviews the papers that exist in the open literature and emphasizes the salient features in retrospect. Then, in prospect, it offers for study a modified composition that would provide a different microstructure under the thermal and deformation conditions for processing a wrought product and thereby improve upon the fatigue crack growth resistance of the present Rene 220 .

\section{Castings and Wrought Processing}

Keh-Minn Chang ${ }^{1}$ introduced Rene $220 \mathrm{C}$ at the 1989 symposium as an alloy that exhibited an enhanced capability of $27^{\circ} \mathrm{C}\left(100^{\circ} \mathrm{F}\right)$ over Alloy 718. It was designed to be strengthened by the bet $\gamma^{\prime \prime}$ phase instead of the fcc $\gamma^{\prime}$ phase observed in most superalloys. It was unique in that it demonstrated the best combination of tensile, rupture and welding properties over such $\gamma^{\prime}$ hardening alloys as waspaloy, Rene 41, Rene 63 and even $\mathrm{P} / \mathrm{M}$ Rene 95 at $704^{\circ} \mathrm{C}\left(1300^{\circ} \mathrm{F}\right)$. Keh-Minn Chang ${ }^{1-2}$ concluded that the unique and successful alloy design of Rene 220 hinged on the requirement of 62.5 pct $(\mathrm{Ta}+\mathrm{Nb})$ with respect to total hardening element content ( $\mathrm{AI}+\mathrm{T} \mathrm{i}+\mathrm{Ta}+\mathrm{Nb})$ in atomic percentage for the formation of the $\gamma^{\prime \prime}$ precipitate. Less than 30 pct (Ta+Nb) will form $\gamma^{\prime}$ precipitates and the co-existence of $\gamma$ and $\gamma^{\prime \prime}$ may occur when the $(\mathrm{Ta}+\mathrm{Nb})$ percentage falls between the above two ranges. cobalt addition remarkably improved rupture life and the optimum amount was determined to be 12 wt pct. A high (Ta+Nb) pct offered better alloy strength with the payoff of alloy stability at high temperatures and $\gamma$ " precipitate strengthening provided superior weldability advantage over alloys hardened by $\gamma^{\prime}$ precipitates.

The feature of Chang's paper ${ }^{1}$ in the 1989 Symposium was Figure 1 which showed that the rupture strength of the new casting Alloy $220 \mathrm{C}$ offered at least $100^{\circ} \mathrm{F}$ advantage in temperature capability over Alloy 718. Also, in a comparison of the two cast alloys, Rene $220 \mathrm{C}$ demonstrated superior tensile and stress rupture properties at $650^{\circ} \mathrm{C}\left(1200^{\circ} \mathrm{F}\right)$ and $704^{\circ} \mathrm{C}\left(1300^{\circ} \mathrm{F}\right)$ even though it was tested at a higher stress level than Alloy 718 at both temperatures in order to attain a meaningful rupture life within reasonable time. Its phase stability was also demonstrated by improved rupture life after $1000 \mathrm{hr}$ exposure at $704^{\circ} \mathrm{C}\left(1300^{\circ} \mathrm{F}\right)$ in comparison to that of the unexposed material. Alloy 718 would suffer a significant degradation of mechanical properties after this long-term exposure. When coupled with the demonstrated castability and weldability, this led to the first usage in combustion cases and turbine frames, major parts of an engine's structure. Because it became possible to fabricate the frame in a single casting and sharply reduce the fabrication cost, Rene $220 \mathrm{C}$ gained acceptance as the advanced alloy for structural castings. 


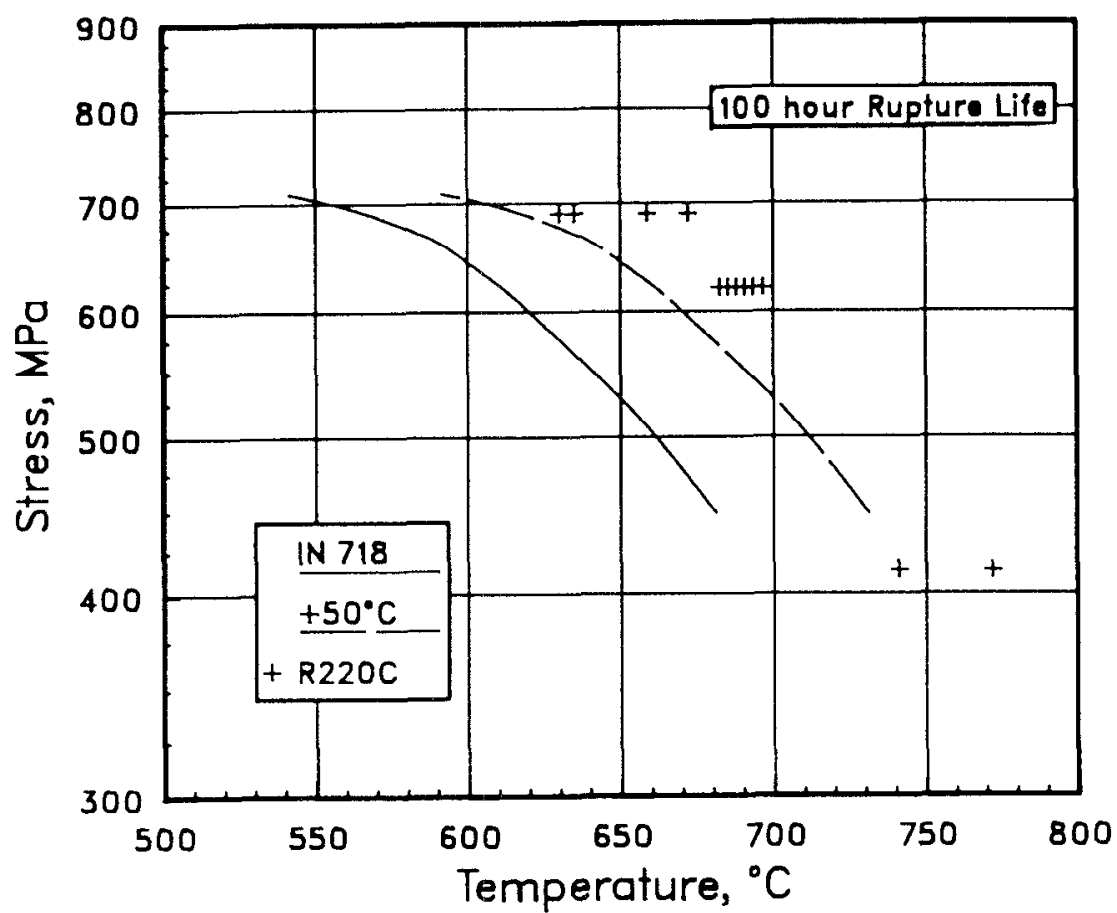

Figure 1 Rupture strength of casting alloy Rene $220 \mathrm{C}$ in comparison with that of Alloy 718 . After Chang. ${ }^{1}$

In the 1991 symposium, Carlson ${ }^{3}$ elaborated on the effects of heat treating conventional cast Rene $220 \mathrm{C}$ and fine grain cast Rene $220 \mathrm{C}$ and he concluded that they not only exhibited different microstructures but had different hardness and impact responses to the imposed heat treatments. The former exhibited a dendritic nature while the latter showed a more equiaxed structure; with both revealing varying amounts of needle-like $\delta$ phase. The CC Rene $220 \mathrm{C}$ had over 2 times the impact strength of the FG Rene $220 \mathrm{C}$ with the value being strongly dependent on the first step in the double-age cycle and with lower temperature resulting in higher values. On the other hand, hardness could be chosen from the heat treatment interaction that optimized parameters for desired properties. In this study of production-size castings, the inherent composite structure of Rene $220 \mathrm{C}$ was reconfirmed but the as cast structure was transient. The fine needle-like $\delta$ phase provides more affective crack-blunting but when sufficient $\mathrm{Nb}$ and $\mathrm{Ta}$ diffused (at temperatures above $1700^{\circ} \mathrm{F}$ for long times) then coarse $\delta$ decorated the grain boundaries and embrittled the material. This is an important problem that occurs in the wrought processing of Rene $220 \mathrm{~W}$ resulting in an unacceptable mechanical property.

In the Superalloys 92 Symposium, wlodek and Field ${ }^{4}$ presented an in-depth metallographic study performed on a simulated turbine case of Rene 220C. The alloy was regarded as a composite of dendrite and interdendritic areas, the latter 

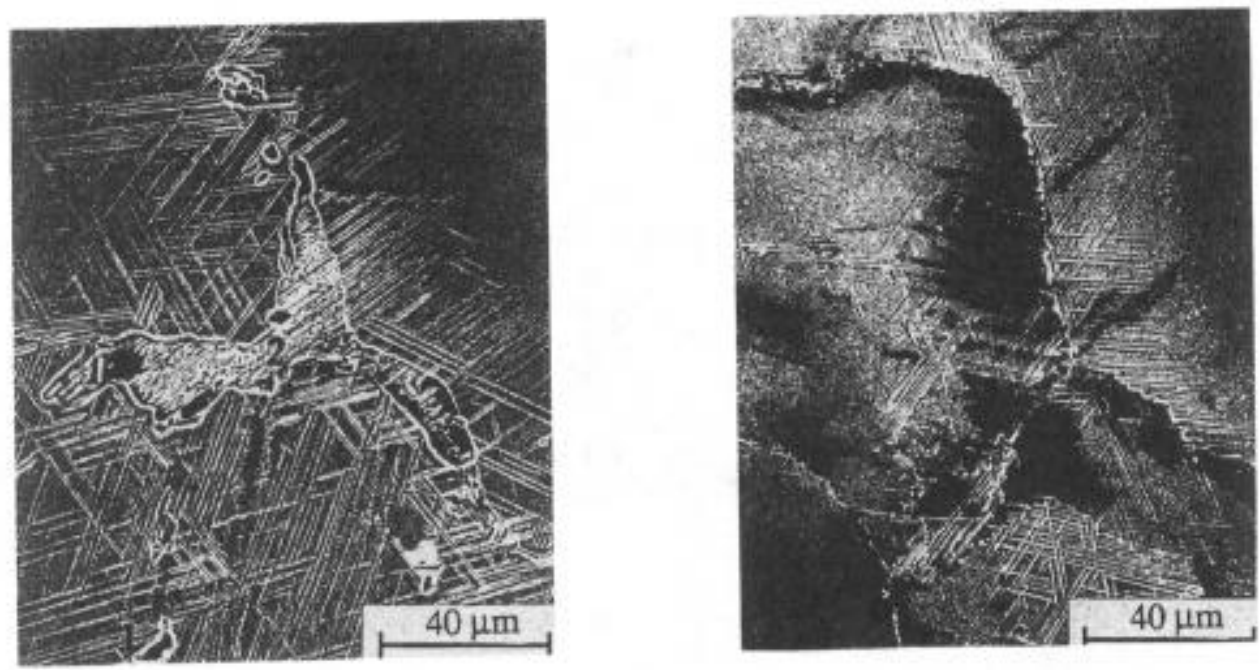

Figure 2 Structure of Rene $220 \mathrm{C}$ as heat treated and after 1000 $\mathrm{hr}$ at $760^{\circ} \mathrm{C}$. (a) Inverse BSE SEM image of large grain boundry MC carbides and orthorbombic $\delta$. (b) Heavy plate concentrations extending well into dendritic regions. After wlodek and Field.

containing heavy concentrations of crack arresting $\delta$ plates, with $\gamma^{\prime}$ and $\gamma^{\prime \prime}$ being the main strengthening phases in both dendritic and interdendritic areas. These three phases constituted up to $38 \mathrm{wt}$ pct of the alloy. The change in the heterogeniety of the cast structure is seen in Figure $2 \mathrm{a}$. The grain boundaries followed the interdendritic areas, well decorated with the kidney-shaped eutectic $\delta$ at grain boundaries, while thin $\delta$ plates appeared both within and at the grain boundaries. The latter was more of a transition zone with fine $\gamma^{\prime}$ surrounding the $\delta$ plates. At higher magnification, the structure of the dendritic areas consisted of $\gamma^{\prime}$ and $\gamma^{\prime \prime}$ precipitates. After exposing this microstructure to $1000 \mathrm{hr}$ at $760^{\circ} \mathrm{C}\left(1400^{\circ} \mathrm{F}\right)$ the two precipitates had grown large enough to allow easy extraction, and a very heavy $\delta$ plate concentration extending into dendritic regions was the prevailing feature, per Figure $2 \mathrm{~b}$. On prolonged exposure in the range of 650 to $815^{\circ} \mathrm{C}$, $\left(1200\right.$ to $\left.1500^{\circ} \mathrm{F}\right)$, Rene $220 \mathrm{C}$ was completely stable in the lower temperature range, but subject to growth and subsequent solutioning of $\gamma^{\prime}$ and $\gamma^{\prime \prime}$ and precipitation of $\delta$ at the high temperature end. In this regard, control of the $\delta$ plate structure would influence fatigue and a certain morphology of the three precipitates would be more effective in impeding crack propagation.

The objective of process development is to produce wrought material in sufficient size and quantity to allow heat treatment development and mechanical property characterization. In the case of Rene $220 \mathrm{~W}$, an example is the Teledyne Allvac triple melt (VIM+ESR+VAR) heat $640 \mathrm{I}$ whose composition has been given by Lawless and Barker. ${ }^{5}$ The ingot produced was 16 inch diameter and its homogenization treatment was different than that 

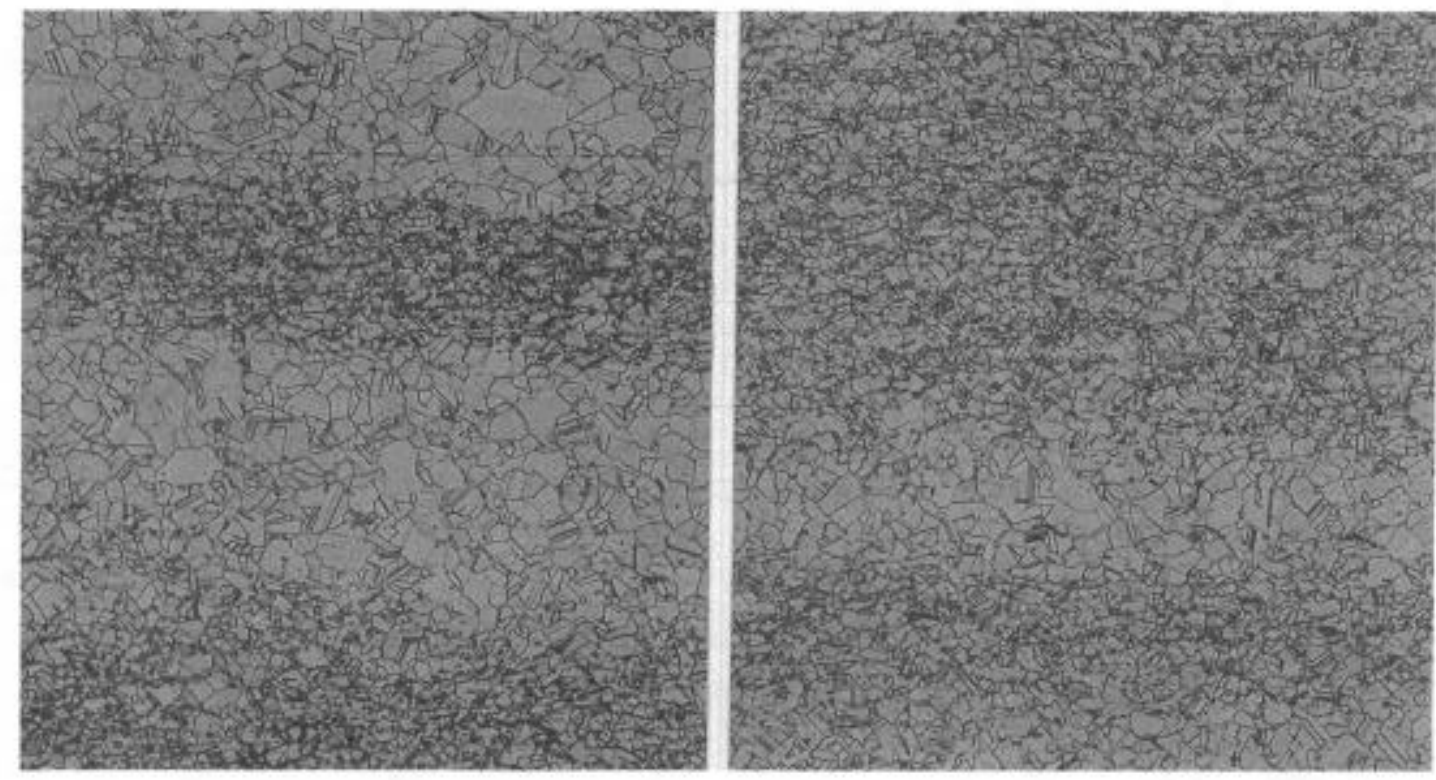

Figure 3 Longitudinal structure in forged Rene 220 billet. (a) T2 end, ASTM8-7 and (b) B2 end, ASTM8. x100. After Teledyne Allvac.

employed on Alloy 718 and deemed proprietary at this time. The ingot was squeezed on a 3,000 ton press to 14 inch diameter in a multiple upset and draw operation. This forged section was then cut almost in half with the larger portion having the original bottom part of the ingot at one end was GFM rotary forged to 8 inch diameter. From this length, a transverse section was cut from the end corresponding roughly to the center of the original ingot (T2) and another piece was cut from the end corresponding to near-the-bottom of the original ingot (B2). The representative microstructures in the longitudinal direction, depicted in Figure 3 , reveal the banding and nonuniform grains that would predict a problem in meeting a certain mechanical property. For this alloy, in particular, more careful attention must be paid to the entire process in an effort to develop an acceptable grain size and microsegregation. The homogenization treatment is critical and a proper one must be developed. It would be coupled with an optimum deformation assisted homogenization practice in the multiple upset and draw operation. Finally, the rotary forging parameters will have to be controlled to provide generally uniform deformation and penetration to the billet center, plus better control of strain distribution in the radial direction and temperature distribution between billet surface and interior during the operation.

\section{Wrought Product Properties}

In the perfection of Rene 220, Chang ${ }^{1-2}$ studied two sizes of heats, $5 \mathrm{lb}$ and $30 \mathrm{lb}$, which were cast in chilled cu molds under partial Ar atmosphere. All ingots were subject to homogenization or HIP processing. To evaluate wrought alloy properties, some homogenized ingots ( 3.5 inch diameter) were 
hammer-forged into plates. Noteworthy was the improvement of temperature capability attained from the chemical composition which transcends from the cast to the wrought form. Figure 4 compares alloy strengths of a forging of co-free Rene $220 \mathrm{~W}$ to Alloy 718. Two important observations stand out which favor Rene $220 \mathrm{~W}$ even without cobalt:

1. With the same yield strength at room temperature, Rene $220 \mathrm{w}$ exhibits a higher tensile strength than Alloy 718. The increase in tensile strength is attributable to the high work hardening rate during the plastic deformation.

2. With the same yield strength at room temperature, Rene 22 ow exhibits higher yield and tensile strengths at intermediate temperatures (up to $1200^{\circ} \mathrm{F}$ ) than Alloy 718 . In other words, the new alloy has strengths less sensitive to temperature.

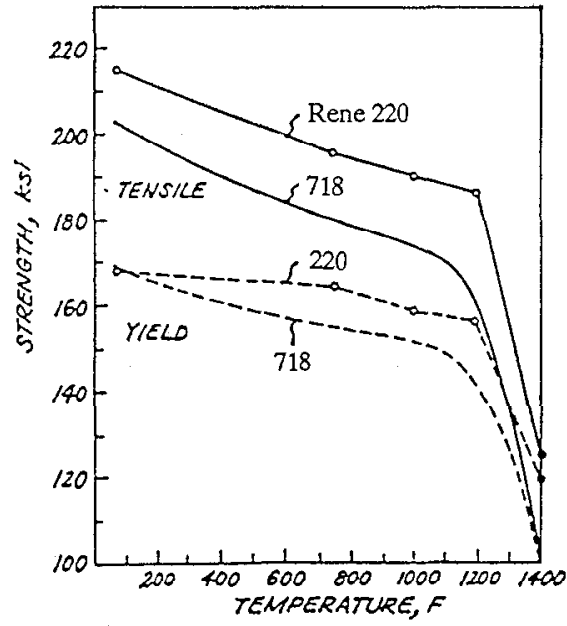

Figure 4 Comparison of tensile and yield strength of wrought Rene $220 \mathrm{~W}$ (without $\mathrm{Co}$ ) and Alloy 718 up to $1400^{\circ} \mathrm{F}$. After Chang. ${ }^{2}$

\section{0-HOUR RUPTURE LIFE}

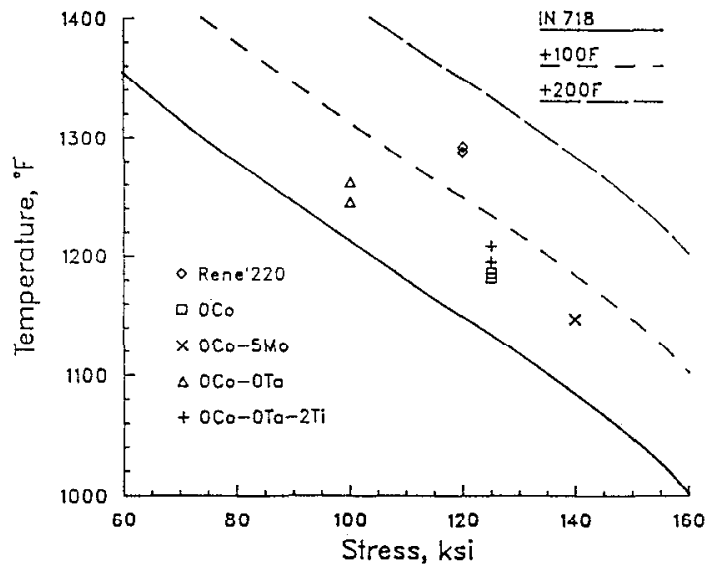

Figure 5 Alloying effects on rupture strength of Rene $220 \mathrm{~W}$. After Chang. ${ }^{2}$

Chang $^{2}$ also carried out extensive studies on the effects of individual alloying elements on the creep rupture properties of the base alloy forgings. The stress rupture data measured on the wrought alloys confirmed the results obtained on the casting alloy series, per Figure 1. Some representative results are presented in Figure 5. The data for Alloy 718 were employed as the references for evaluating the improvement. Stress rupture life of each alloy measured at $1200^{\circ} \mathrm{F}$ under an initial stress level chosen to be 80 pct of the alloy yield strength. Three important correlations between the alloy chemistry and the improvement of temperature capability were established: 
1. A proper amount of Co addition is the essential ingredient for the rupture properties of Rene 220. Introducing 12 wt\% Co provides more than an order of magnitude increase in stress rupture life at $1200^{\circ} \mathrm{F}$.

2. Increasing the hardening element content, e.g., Ti or Ta, can improve the alloy strength and subsequently enhance rupture life. The improvement from adding $\mathrm{Ti}$ or $\mathrm{Ta}$ without Co addition is limited.

3. Increase in refractory element addition, for example Mo, has little effect on the rupture properties.

Wrought Rene $220 \mathrm{~W}$ has the required strength properties for advanced turbine applications based on the results obtained by Chang $^{1-2}$ in the processing of small ingots. Hence, it would be an attractive alloy to replace Alloy 718 where creep has become a limiting property, and the alloy demonstrated acceptable high temperature crack growth resistance in these small (thin) sections. Thus, the view of the designers was that the superior temperature capability from a creep standpoint would be enough to use Rene $220 \mathrm{~W}$, with the expectation that the other properties would be be about equal. Later, the technical group found that this was not the case in thicker sections and felt that damage tolerance should be the basis of selection. Thus, Rene $220 \mathrm{~W}$ suffered from this sequence of events while the different expectations for Rene $220 \mathrm{C}$ permitted the cast version to gain commercial acceptance.

Investigating the thin section aspect further, Lawless and Barker ${ }^{5}$ employed a variety of thermomechanical treatments in the

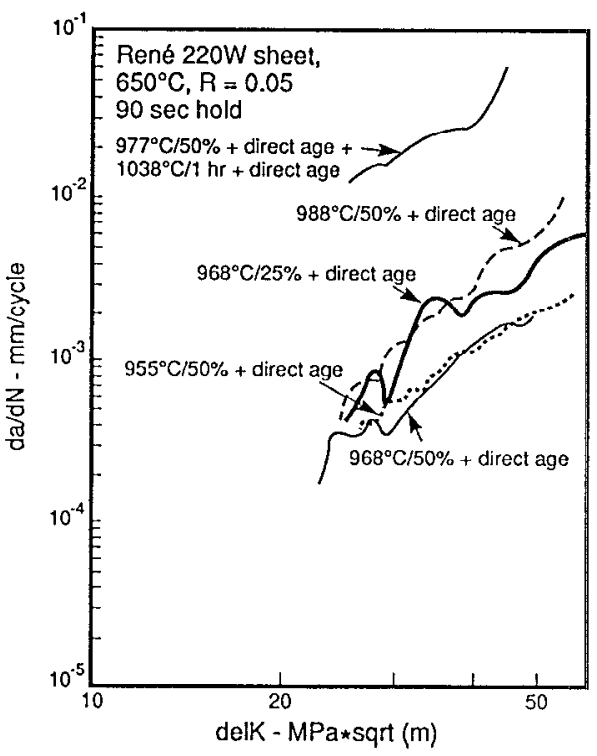

Figure 6 Hold time $(1.5 \mathrm{sec}-90 \mathrm{sec}-1.5 \mathrm{sec})$ crack growth behavior of Rene'220W sheet at $650^{\circ} \mathrm{C}$.

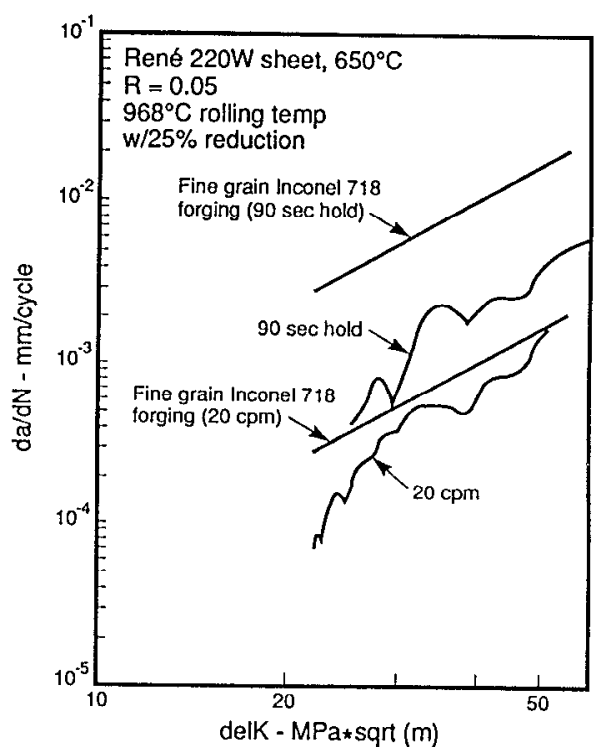

Figure 7. Continuous cycling and hold time crack growth behavior of Rene'220w sheet $\left(968^{\circ} \mathrm{C}\right.$ rolling temperature and
$25 x$ reduction) vs. flne grain Inconel 718 forging at $650^{\circ} \mathrm{C}$ 
sheet rolling of a slice cut from the above 8 inch diameter billet from heat 6401, and they found that the crack growth and creep rupture behavior was sensitive to the specific TMP path. The range in hold time crack growth rates obtained at $650^{\circ} \mathrm{C}$ was greater than 10x, per Figures 6 and 7 . The preferred processing approach produced a warm-worked, directional microstructure with

few, if any, recrystallized grains and with creep and rupture properties about $100^{\circ} \mathrm{F}$ better and hold time crack growth behavior far superior to fine grain 718. For a total reduction in thickness of 50 pct, the amount of $\delta$ plate precipitation was maximized at the lowest rolling temperature of $955^{\circ} \mathrm{C}$. In this condition, the alloy exhibited the best crack growth behavior and the worse creep/rupture behavior. Decreasing the final rolling reduction from 50 pct to 25 pct produced a large increase in creep/rupture resistance with only a small decrease in hold time crack growth resistance, and the program goals were met. As in Rene $220 \mathrm{C}$, optimum strengthening in Rene $220 \mathrm{~W}$ sheet was associated with the formation of the $\gamma^{\prime} / \gamma^{\prime}$ "sandwich" structure.

Lawless and Barker ${ }^{5}$ admit that their TMP approach, while feasible in sheet form, may be difficult to transfer to a production process for thick sections. The deformation conditions and the cooling rates in forging thick sections, such as a turbine disk or shaft, are much different than those occurring in sheet fabrication from a billet slice or chang's laboratory heats that were either hammer forged or hot swaged to small diameter bar. During the thermal treatments in producing a thicker section forging, the $\delta$ plates precipitate in the interdendritic areas and various morphologies of $\gamma^{\prime}$ and $\gamma$ " form in both dendritic and interdendritic areas. Thus, they can appear in different configurations depending upon the uniformity of deformation during forging and the ensuring cooling rate in a thick section.

The problem is to obtain a more uniform microstructure across the thickness of a Rene $220 \mathrm{~W}$ forging that will produce the fracture surface that correlates with slower FCCR. The slower solidification rate in a thicker section and the consequent, hence greater dendritic segregation will contribute to an uneven configuration of the precipitation phases. Principally, the ability to produce forgings with acceptable, predictable properties is dependent upon achieving a controlled, uniform grain growth during the operation. Abnormal or critical grain growth in a Rene $220 \mathrm{~W}$ forging, coupled with an uneven distribution of the precipitation phases, will produce unacceptable properties. Hence, a detailed study of the strain and strain rate deformation during isothermal forging and heatup rate to the solution temperature is necessary. Also, because of a strong correlation between mechanical properties and cooling rates from the solution temperature, the proper cooling rate (quench) medium must be determined and equally important to defining the cooling rate required to meet property goals is defining the alloy's susceptibility to quench cracking. 
The vendors have employed TMP as a routine method to control the structure and properties of Alloy 718. In production-scale simulations employing conventional practice, Rene 22 oW has shown hold time crack growth rates that are unacceptable. Optimum TMP conditions for Rene $220 \mathrm{~W}$ require an extensive forge study since the temperature and phase transformation relationship is significantly different between Rene 220 and Alloy 718 . Chang ${ }^{6}$ has suggested a forging procedure but it has not been tried commercially because it would entail a considerable expense in modifying the in-place forging procedure with the major part of it to be assumed by the alloy developer/user. This, coupled with the opinion of some skeptics that Rene 220 is overalloyed for a uniform structure in a cast and wrought product, has shelved Rene $220 \mathrm{~W}$ and production has been limited to the investment cast version, Rene $220 \mathrm{C}$, where the problem is not apparent.

\section{Alloy Modification}

The single disadvantage of using $\gamma "$ strengthening in Ni-based superalloys is the phase instability after prolonged exposure at high temperature. The $\gamma$ " precipitate phase is not the equilibrium phase and it will be replaced, when overaged, by the stable 6 phase which degrades the alloy system. The results show that the stability of the $\gamma$ " precipitation phase in Rene 220 is greater than the $\gamma$ " precipitation phase in conventional 718 and it is attributed to the difference in the amounts of the hardening elements. Even in the case of Alloy 718, minor modifications of its composition via changes in the amounts of the hardening elements coupled with an appropriate heat treatment results in better thermal stability properties via smaller size and spacing of the $\gamma^{\prime} / \gamma^{\prime \prime}$ precipitates. ${ }^{8-9}$

One approach, of current interest, in attaining a more stable microstructure is the development of a cuboidal, compact $\gamma^{\prime} / \gamma^{\prime \prime}$ precipitate. Pineau and others ${ }^{10-11}$ have demonstrated that relatively small modifications in the $\mathrm{Ni}-\mathrm{Cr}-\mathrm{Fe}$ base Alloy 718 , providing a larger $(\mathrm{Al}+\mathrm{Ti} / \mathrm{Nb})$ ratio coupled with a proper heat treatment produces a so-called compact morphology consisting of small $\gamma^{\prime}$ precipitates which are framed by $\gamma^{\prime \prime}$ precipitates. Evidence that this cuboidal precipitates morphology has a better possibility of providing thermal stability above $650^{\circ} \mathrm{C}$ is seen in the microstructure of the modified 718 compared to the conventional 718 after aging for $1000 \mathrm{hr}$ at $750^{\circ} \mathrm{C}\left(1380^{\circ} \mathrm{F}\right)$ per Figures 8 and 9. The smaller size and greater density of the precipitates coupled with far less $\delta$ formation at grain boundaries provided a greater retention of the original hardness. Whether it is the compact $\gamma^{\prime} / \gamma^{\prime \prime}$ precipitate structure or the lesser amount of $\delta$ phase, or the combination, that contributes to this result is not answered. And, it should be noted from the hardness curves, per Figure 5 in reference 10 , that even though the hardness of the modified 718 alloy drops to a far lesser degree than conventional 718 it is still an indication of phase in instability at $750^{\circ} \mathrm{C}$. 

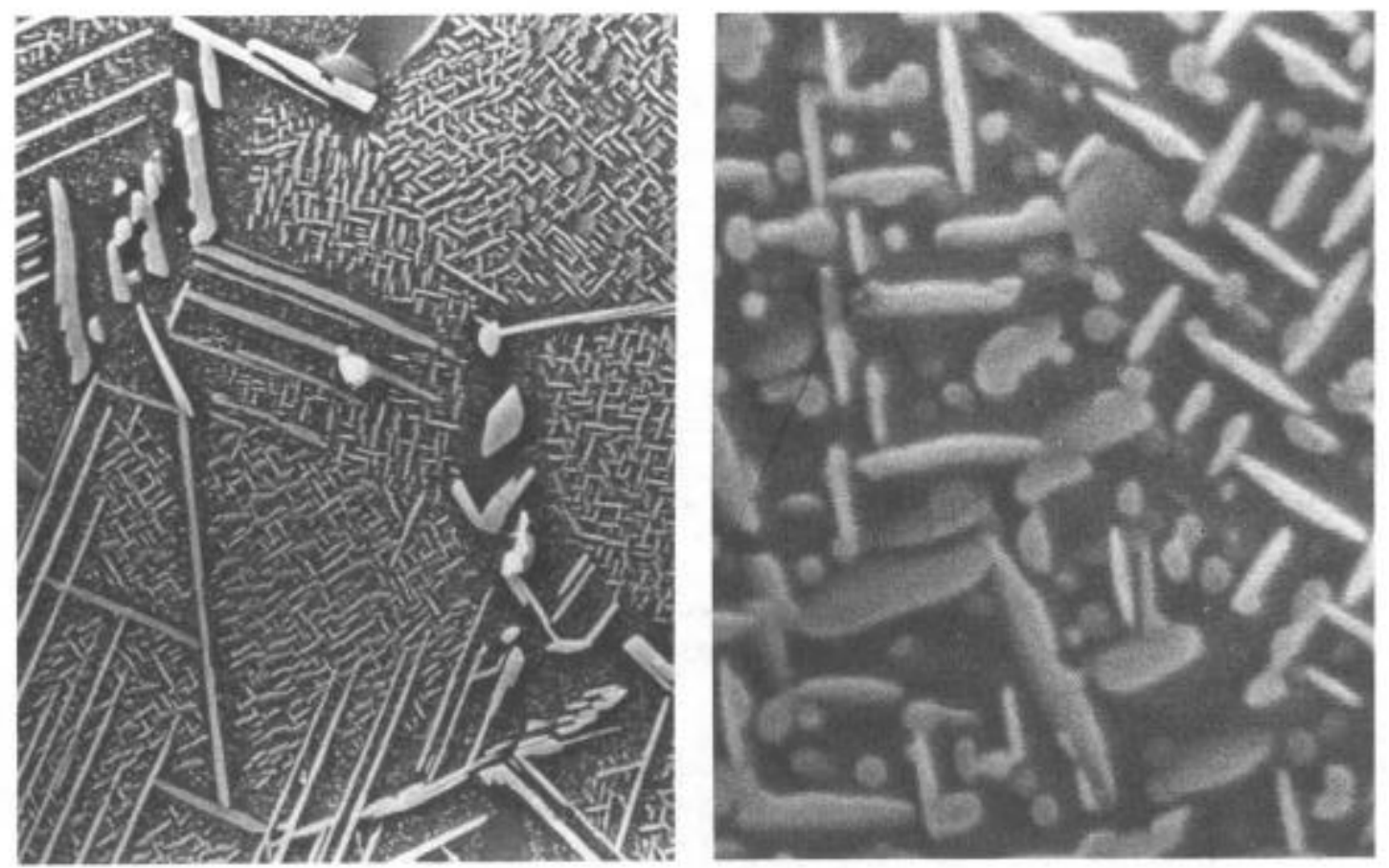

Figure 8 Precipitate structure in conventional Alloy 718 after aging for $1000 \mathrm{hr}$ at $750^{\circ} \mathrm{C}$ at (a) $\times 9400$ and (b) $\times 75000$. After Andrieu. ${ }^{11}$
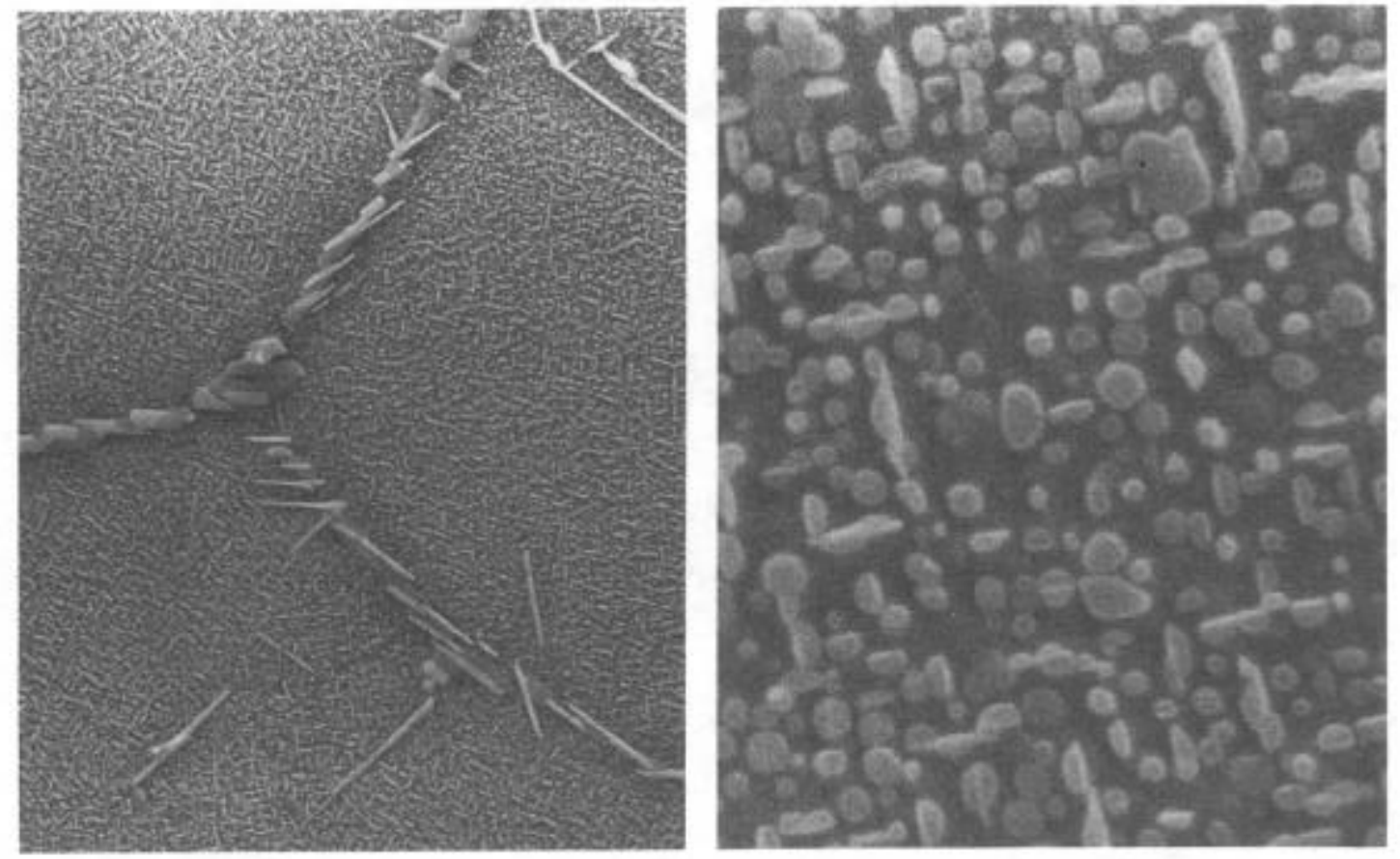

Figure 9 Precipitate structure in modified Alloy 718 after aging for $1000 \mathrm{hr}$ at $750^{\circ} \mathrm{C}$ at (a) $\times 7500$ and (b) 60000 . After Andrieu. ${ }^{11}$ 


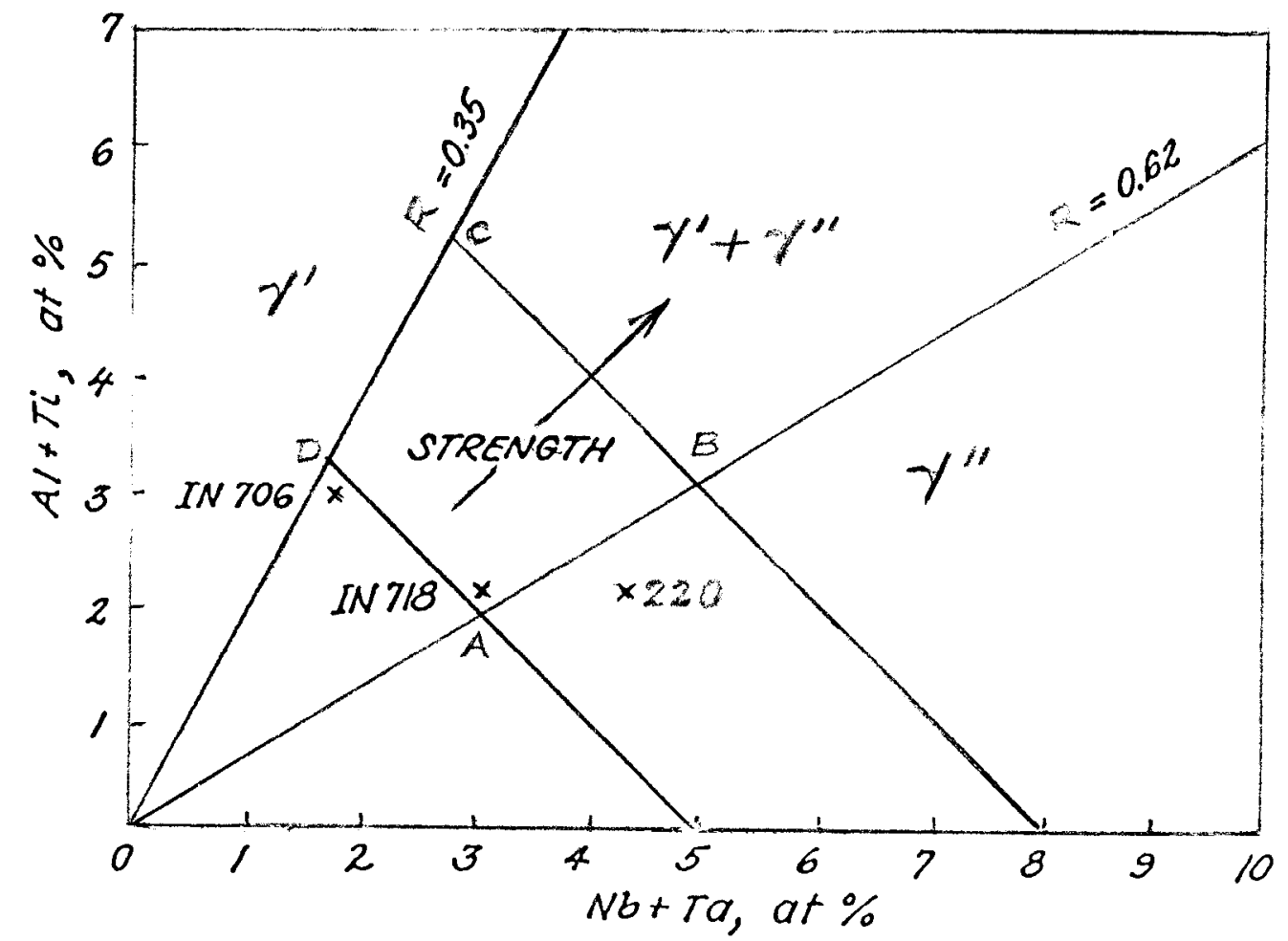

Figure 10 Relationship between $(\mathrm{Al}+\mathrm{Ti})$ and $(\mathrm{Nb}+\mathrm{Ti})$ required for the production of Rene 220 and the area bounded by ABCD wherein a modified Rene 220 having a cuboidal $\gamma^{\prime} / \gamma^{\prime \prime}$ precipitate structure could be developed. After Chang. ${ }^{2}$

In the development of the present Rene 220 composition, chang ${ }^{1-2}$ established that the precipitate structure and quantity depended upon the percentage of $(\mathrm{Ta}+\mathrm{Nb})$ substitution. Low $\left(\mathrm{I}^{\mathrm{a}} \mathrm{a}+\mathrm{Nb}\right)$ percentage formed $\gamma^{\prime}$ which had a spherical-to-cuboidal morphology. When sufficient $(\mathrm{Ta}+\mathrm{Nb})$ replaced (Al+Ti), almost equal volume fractions of $\gamma^{\prime}$ and $\gamma^{\prime \prime}$ particles were observed. Further increase in $(\mathrm{Ta}+\mathrm{Nb})$ percentage above 62.5 pct converted all precipitate phases into $\gamma$ ". These basic factors would have to be considered in any modification of the Rene 220 composition that could provide acceptable mechanical properties coupled with improved hold time crack growth resistance for wrought products.

The possibility exists that the compact (cuboidal) precipitate structure can also be formed in the $\mathrm{Ni}-\mathrm{Cr}-\mathrm{Co}$ base of Rene 220 and it could result in a modified composition that would have an acceptable (better) hold time crack growth resistance coupled with comparable thermal stability properties of the present Rene $220 \mathrm{~W}$. As seen in Figure 10, there are regions that form mixtures of $\gamma^{\prime}+\gamma^{\prime \prime}$ and a composition would have to be found where the ratio $\mathrm{R}=(\mathrm{Nb}+\mathrm{Ta}) /(\mathrm{Al}+\mathrm{T} \mathrm{i}+\mathrm{Ta})$ will form the compact $\gamma / \gamma$ " precipitate after an appropriate heat treatment. The two lines which pass through the origin of the graph delineate the three different precipitation mechanisms. The mixed $\gamma^{\prime}+\gamma^{\prime \prime}$ mechanism prevails in the area of ABCD wherein the $R$ value is between 0.35 
and 0.62 . The approach would be to take the Ni-Co-Cr matrix of Rene 220 and select four or five compositions with appropriate $R$ values within the region and determine if the cuboidal $\gamma^{\prime} / \gamma^{\prime \prime}$ structure can be developed after an appropriate heat treatment. One might predict that 50 pct of each phase would be optimum. If successful, a couple of larger heats will be necessary to narrow the composition that will produce the structure and provide mechanical properties. If the cuboidal $\gamma^{\prime} / \gamma^{\prime \prime}$ precipitate structure can be produced, coupled with a different $\delta$ phase distribution, there is a good possibility that this modification will provide a better combination of properties than obtained in the present Rene $220 \mathrm{~W}$.

\section{References}

1. K-M. Chang and A.H. Nahm, Superalloy 718: Metallurgy and Applications, TMS (1989), pp. 631-646.

2. K-M. Chang, US Patent 4981644, January 1, 1991, 20 pp.

3. R.G. Carlson, Superalloys 718,625 and Various verivatives, TMS, (1991), pp. 851-863.

4. S.T. Wlodek and R.D. Field, Superalloys 1992, TMS (1992), pp. 477-486.

5. B.H. Lawless and J.F. Barker, Superalloys 1992, TMS (1992), pp. 53-62.

6. K-M Chang, US Patent 5061324, February 11, 1992, 15 pp.

7. E. Guo, F. Xu and E.A. Loria, Superalloys 718: Metallurgy and Applications, TMS (1989), pp. 567-576.

8. J.K. Tien et al, High Temperature Materials for Power Engineering 1990, CRM Leige, 1990, pp. 1341-1356.

9. E. Andrieu, R. Cozar and A. Pineau, Superalloy 718: Metallurgy and Applications, TMS (1989), pp. 241-256.

10. E.A. Loria, JOM (June 1992), pp. 33-36.

11. E. Andrieu, private communication (September 1991). 